\title{
A Microcomputer Assessment System (MAS) for administering computer-based surveys: Preliminary results from administration to clients at an impaired-driver treatment program
}

\author{
RON D. HAYS, JAMES J. GILLOGLY, LAURAL HILL, MATTHEW W. LEWIS, \\ and ROBERT M. BELL \\ RAND, Santa Monica, California \\ and \\ RONALD NICHOLAS \\ Center for Counseling, Tarzana, California
}

\begin{abstract}
The Microcomputer Assessment System (MAS), written in C language, allows a researcher to design and administer computer-based surveys by manipulating ASCII text files and requires no knowledge of a traditional programming language. The system was designed to provide maximum user flexibility: MAS allows both multiple-choice and open-ended (fill-in) questions and allows control over text color, allowable answers, and summary output. MAS also assesses response latency and includes support for random assignment of different instruments to respondents. MAS runs under MS-DOS 3.0 or higher, requires $640 \mathrm{~K}$ of RAM, a color screen (EGA or better), and an extended keyboard. Preliminary results from an application of MAS to a sample of 121 clients at an impaired-driver treatment program are summarized.
\end{abstract}

Self-reports of alcohol use have widespread application in impaired-driver treatment programs because other satisfactory and practical measures are generally unavailable (cf. Sobell, Maisto, Sobell, \& Cooper, 1979; Williams, Aitken, \& Malin, 1985). Alcohol-use self-reports may be influenced by the nature of response options offered (Hesselbrock, Babor, Hesselbrock, Meyer, \& Workman, 1983; Poikolainen \& Karkkainen, 1985), the nature of the setting in which they are given (Gfroerer, 1985), and whether reports are about use of alcohol in specific settings or generic use (Hilton, 1986). Babor, Stephens, and Marlatt (1987, p. 420) concluded that "alcohol research would benefit from a new generation of methodological research directed at procedures that enhance the validity of verbal report data.... The use of computerized assessments may yield more valid data ... than other techniques." Clearly, there is a need to examine alternatives to traditional paper-and-pencil surveys that will minimize errors of measurement of alcohol use (Allen \& Skinner, 1987; Skinner \& Allen, 1983).

We have developed a data-collection program that allows a researcher to design and administer computer-

Preparation of this article was supported in part by Grant 07852 from the National Institute on Alcohol Abuse and Alcoholism. The opinions expressed are those of the authors and do not necessarily reflect the views of RAND or the sponsor. The authors appreciate the comments of five anonymous reviewers on an earlier version of this manuscript. Thanks are due to Karen Boseker for outstanding secretarial support. Correspondence concerning this article should be addressed to R. D. Hays, RAND, 1700 Main Street, Santa Monica, CA 90407-2138. based surveys by manipulating ASCII text files and that requires no knowledge of a traditional programming language. This paper summarizes the development of the program and preliminary results of its use in a pilot sample of 121 clients at a treatment program for persons convicted of impaired driving.

\section{FEATURES OF MICROCOMPUTER ASSESSMENT SYSTEM}

Because of the flux in the state of the art of microcomputer programs for survey administration and our desire to tailor a program to our specifications and ensure quality control, we decided to develop a new datacollection program, the Microcomputer Assessment System (MAS). Our key data-collection requirements included administrator- and respondent-friendliness, portability, long-distance manageability, stand-alone system, randomization of administered items to different respondents, and capacity to accommodate a lengthy survey battery. MAS was designed to provide maximum user flexibility: it allows both multiple-choice and open-ended (fill-in) questions and allows control over text color, allowable answers, and summary output. MAS also assesses response latency (i.e., time to response for each item).

MAS is written in C language (Borland $\mathrm{C}++$ compiler) and runs under MS-DOS 3.0 or higher, requires $640 \mathrm{~K}$ of RAM, a color screen (EGA or better), and an extended keyboard. Questions and response options are presented in the default font, 25 lines of 80 characters, using 
Table 1

Special Characters Used in Instructions and Item Input Files

\begin{tabular}{|c|c|}
\hline Characters & Description \\
\hline$\#$ & Comment-used for putting a blank line in a question \\
\hline$<$ blank $>$ & Blank line separates questions from answers \\
\hline * & Terminate a question \\
\hline ** & Terminate a question with multiple answers allowed \\
\hline *! & Terminate an optional question \\
\hline **! & Terminate an optional question with multiple answers allowed \\
\hline$\$$ text & Terminate a question that will be summarized; title is "text" \\
\hline$\$ \$$ texi & Terminate a summarized question with multipie answers \\
\hline$\$ !$ text & Terminate an optional summarized question \\
\hline$\$ \$ !$ text & Terminate an optional summarized question with multiple answers \\
\hline digit & $1-9$ to indicate the value assigned to this answer for scoring \\
\hline \multicolumn{2}{|c|}{ Other special characters: } \\
\hline$=(2-10)$ & Fill-in answer with allowed values from 2 to 10 , for example \\
\hline$\backslash=$ & Used to hide an " =" from the fill-in hack so $=$ can be in question \\
\hline
\end{tabular}

Table 2

Example Input for Multiple-Choice Item

MICROCOMPUTER ASSESSMENT SYSTEM

\#

What day is it?

MONDAY

TUESDAY

WEDNESDAY

THURSDAY

FRIDAY

SATURDAY

SUNDAY

Table 3

Screen Display for Multiple-Choice Item

MICROCOMPUTER ASSESSMENT SYSTEM

What day is it?

MONDAY

TUESDAY

WEDNESDAY

THURSDAY

FRIDAY

SATURDAY

SUNDAY

Use up and down arrows to point, and SPACE to select.

Left and right arrows to go forward and back, ENTER to proceed. 
administrator-selected color cues to distinguish among the question, the selected response, unselected response options, and instructions.

\section{Program Interface}

The program interface was derived through an evaluation of existing programs and a series of brainstorming meetings among project staff. MAS was designed to allow self-administration of surveys by computer with minimal outside assistance. The program relies on the use of a limited number of keys: the software ignores keystrokes for the remaining keys. Color is used to initially distinguish response choices from item stems, and when a response is selected, the color is changed to match the item stem.

\section{Input Elements}

Instructions and items. Instructions to respondents and questionnaire items are read by MAS from ASCII files created by the administrator. A simple set of special characters embedded in the ASCII files is used to communicate that a question can have multiple responses, has a write-in response, is optional, or is to be included in the output summary, and to indicate where blank lines of text should be displayed (see Table 1). An example of an input file for a multiple-choice item is provided in Table 2 . The file consists primarily of text that will be presented verbatim to the respondent with one pound (waffle, octothorp, number sign, splat) character denoting the placement of a blank line. This type of item is terminated with a single asterisk. The screen display associated with this input file is provided in Table 3.

An example of the input for an item with multiple answers allowed is given in Table 4. Again, the file consists primarily of text that will be presented verbatim to the respondent with one pound character denoting the placement of a blank line. In addition, the column of numbers in the left corner informs MAS about the weights to use in calculating a summary score for this question (i.e., unit weighted except for zero weight for a response of "None of the Above"). This type of item is terminated with double asterisks. The screen display associated with this input file is provided in Table 5.

Table 4

Example Input for Item with Multiple Responses Allowed

\section{MICROCOMPUTER ASSESSMENT SYSTEM}

\#

Which of the following statements are TRUE of you?

(Please select all that apply)

1 I DRINK TO CALM MY NERVES.

1 I FEEL LIKE CONTINUING TO DRINK WHEN OTHERS HAVE STOPPED.

1 I FEEL UNCOMFORTABLE IN SITUATIONS WHEN ALCOHOL IS NOT

AVAILABLE.

I DRINK ALCOHOL TO GET RELIEF.

I HAVE MEMORY LAPSES AFTER DRINKING.

I THINK ABOUT OR LOOK FORWARD TO THE TIMES WHEN I CAN DRINK

ALCOHOL.

I GET IRRITATED WHEN MY DRINKING IS DISCUSSED BY OTHERS.

MY TOLERANCE TO ALCOHOL HAS INCREASED.

NONE OF THE ABOVE

Table 5

Screen Display for Item with Multiple Responses Allowed

\section{MICROCOMPUTER ASSESSMENT SYSTEM}

Which of the following statements are TRUE of you?

(Please select all that apply)

I DRINK TO CALM MY NERVES.

I FEEL LIKE CONTINUING TO DRINK WHEN OTHERS HAVE STOPPED.

I FEEL UNCOMFORTABLE IN SITUATIONS WHEN ALCOHOL IS NOT

AVAILABLE

I DRINK ALCOHOL TO GET RELIEF.

I HAVE MEMORY LAPSES AFTER DRINKING.

I THINK ABOUT OR LOOK FORWARD TO THE TIMES WHEN I CAN DRINK ALCOHOL.

I GET IRRITATED WHEN MY DRINKING IS DISCUSSED BY OTHERS. MY TOLERANCE TO ALCOHOL HAS INCREASED. NONE OF THE ABOVE

Use up and down arrows to point, and SPACE to select. Left and right arrows to go forward and back, 'ENTER to proceed. 
Table 6

Example Input for Open-Ended (Fill-In) Item MICROCOMPUTER ASSESSMENT SYSTEM

$\#$

How old were you on your last birthday?

AGE: $\quad=(1-99)$
Table 7

Screen Display for Open-Ended (Fill-In) Item

MICROCOMPUTER ASSESSMENT SYSTEM

How old were you on your last birthday?

AGE:

Please enter a number from 1 to 99 .

Left and right arrows to go forward and back, ENTER to proceed.

Table 8

Example General Configuration File

Test directory: pilot

Print summary: no

\# The following number is added to the sequence number for reporting

ID offset: 1000

Randomization: rfile

Sequence file: sequence

Report name: reports

Summary file: summary

\# Color selection section

\# Legal background colors are:

BLACK, BLUE, GREEN, CYAN, RED, MAGENTA, BROWN, and LIGHTGRAY

Legal foreground colors include those and:

DARKGRAY, LIGHTBLUE, LIGHTGREEN, LIGHTCYAN, LIGHTRED, LIGHTMAGENTA,

YELLOW, and WHITE.

Questioncolor:

Highlightfore:

Highlightback:

Normalback:

LIGHTCYAN

LIGHTCYAN

Normalfore: LIGHTGRAY

Selectedfore: $\quad$ LIGHTCYAN

Selectedback: BLACK

Divider: LIGHTRED

Instructionfore: LIGHTGRAY

Instructionback: BLACK

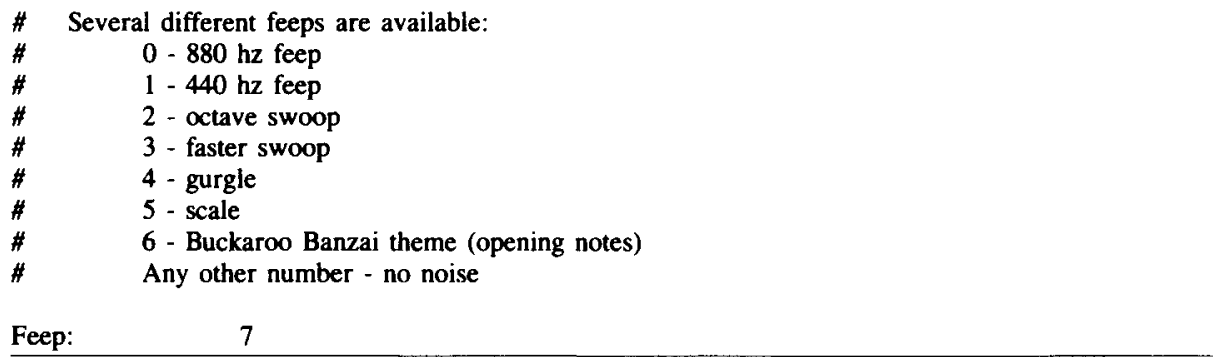


Table 9

Example Specific Configuration File

\begin{tabular}{lll}
\hline Test: & pilot.ins & INSTRUCTIONS \\
Start timer: & \\
Test: & pilot.ron & READING ASSESSMENT \\
Test: & pilot.han & HANG OF IT \\
Test: & pilot.bac & BACKGROUND \\
Test: & pilot.sdr & SDRS \\
Test: & pilot.lif & LIFE EVENTS \\
Test: & pilot.fla & FREQUENCY OF ALCOHOL USE \\
Test: & pilot.per & YOUR PERCEPTIONS \\
Test: & pilot.in2 & SELECT ALL THAT APPLY INSTRUCTIONS \\
Test: & pilot.jel & JELLINEK \\
Test: & pilot.cag & CAGE \\
Test: & pilot.drv & DRIVING-RELATED \\
Test: & pilot.dru & DRUG USE \\
Test: & pilot.qua & QUANTITY OF ALCOHOL USE \\
Test: & pilot.you & HALFWAY \\
Test: & pilot.res & RESPONSIVENESS TO AA \\
Test: & pilot.aud & AUDIT \\
Test: & pilot.med & MEDICATION USE \\
Test: & pilot.dpr & DRINKING IS A PROBLEM \\
Test: & pilot.mas & MAST \\
Test: & pilot.und & UNDER THE INFLUENCE \\
Stop timer: & \\
Test: & pilot.com & COMPUTER ANXIETY \\
Test: & pilot.end & END \\
\hline
\end{tabular}

An example of the input for an open-ended (fill-in) item is given in Table 6. A pound character is used four times in this example to insert four blank lines. The fill-in nature of the item is communicated by using a bracketed numeric range. This type of item is terminated with a single asterisk. The screen display associated with this input file is provided in Table 7.

Configuration files. MAS accesses two types of configuration files: general and specific. The general configuration file indicates where the items to be administered are stored, the names of general input and output files, the display color, and the sound "feep" to use following each response (see Table 8). MAS tracks the sequential number of each respondent. This number is used as an index into a file of randomly ordered numbers to select a specific configuration file that determines which instruments to administer and in what order to administer them.

The specific configuration files are linked to the randomization option of MAS so that each file represents a different assigned condition. These files communicate which questions to administer to respondents assigned to the condition and the order of administration. In addition, placement of two special commands (start and stop timer) is used to designate a block of the interview whose time of administration will be summarized in the output files (see Table 9).

\section{Output Elements}

MAS saves an ASCII output file that contains the responses to each item and response times (see Table 10). In the pilot study (see below), these raw data are sent from the data-collection site to RAND by modem using the
UUPC file-transfer package and are then translated to a standard analytic raw-data format using a PERL program we designed. Data are then analyzed using standard software packages (e.g, SAS). MAS also prints out a onepage feedback sheet that summarizes responses given by the respondent. Example output is given in Table 11.

\section{PILOT STUDY OF MAS}

\section{Method}

Subjects. One hundred and twenty-one clients ( 91 males, 20 females) at a West Coast treatment center for impaired drivers were sampled. The center was chosen because its clients are representative of the driving-under-the-influence (DUI) offenders required by the courts to attend treatment programs in the Los Angeles area.

The average age of the respondents was 33 years, with a range from 20 to 75 . Eighty-eight percent of the sample were non-Hispanic white, $88 \%$ were high-school graduates, and $26 \%$ were married and living with their spouses. Yearly household income was below $\$ 30,000$ for $51 \%$ of the sample.

The respondents reported an average of 1.6 convictions in the last 7 years for driving under the influence and an average blood alcohol concentration of 0.16 at the time of the last arrest, and $21 \%$ reported one or more automobile accidents during the last 12 months. In the sample, $26 \%$ categorized themselves as alcoholic, $15 \%$ as problem drinkers, $39 \%$ as social drinkers, and $12 \%$ as light drinkers, and $7 \%$ reported drinking only on special occasions.

Measures. One hundred and twenty-five questions were posed to participants in the pilot study. Included in the 
Table 10

Example Raw Data Output

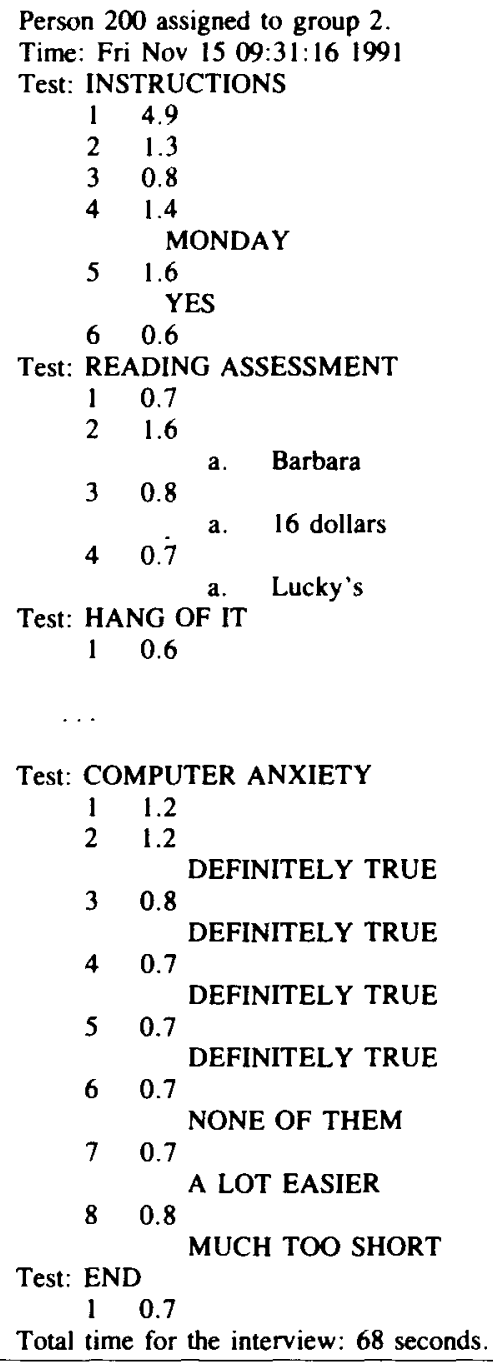

battery were the CAGE (Mayfield, McLeod, \& Hall, 1974), a revised version of the AUDIT (Babor \& Grant, 1989), the short form of the MAST (Selzer, Vinokur, \& Van Rooijan, 1975), and a short-form measure of socially desirable response set (Hays, Hayashi, \& Stewart, 1989).

A short reading assessment, sociodemographic items, life events, drug use, and several additional questions about alcohol use were also included. The order of administering the frequency of alcohol-use items within the interview and the nature of response options for these items were randomized to respondents.

\section{Results}

Average time to complete the 125 -item questionnaire was $32 \mathrm{~min}(S D=11$, range of 16-76 min). Internalconsistency reliability estimates (Cronbach, 1951) for the five multi-item measures included in the study were .60 or higher: short-MAST (.85), AUDIT (.85), CAGE (.64),
SDRS-5 (.61), and computer anxiety (.72). These reliabilities are comparable to those reported in previous studies for identical or similar measures when administered by paper and pencil (Hays et al., 1989; Meier \& Lambert, 1991; Selzer et al., 1975; Zung, 1979), although the estimated internal-consistency reliability of the CAGE was notably higher in a previous study (Fleming \& Barry, 1991).

Reaction of respondents to the computer interview was generally very favorable. The majority of the respondents indicated that they did not feel uneasy $(82 \%)$, tense $(87 \%)$, or nervous $(90 \%)$ using the computer. In addition, most respondents had no problems using the computer $(59 \%$ responded "definitely true" and 19\% "mostly true"). Eighty-one percent of the clients said they answered all of the questions in the interview honestly, and the remainder reported answering most of them honestly. In comparison to answering the questions by a counselor, 
Table 11

Example Feedback Sheet

Time: Tue Jul 16 16:49:54 1991

Person 3 assigned to group 5 .

AGE:

GENDER:

RACE:

MARITAL STATUS:

EDUCATION:

INCOME:

N OF PEOPLE INCOME SUPPORTS:

LANGUAGE SPOKEN:

PROGRAM BEGINNING:

DAYS OF LAST WEEK ALCOHOL USE:

DRINKING NOW IS:

TREATMENT GOAL:

TREATMENT GOAL:

ALCOHOLISM IS:

CLIENT IS:

FEET:

INCHES:

WEIGHT:

BAC:

INTOXICATION DURING DUI:

TAKE CRITICISM WELL:

MEDICATION USE LAST 6 MONTHS

HISTORY OF COUNSELING:

DRINKING IS A PROBLEM NOW:

LONGEST TIME SOBER LAST YEAR:

WANTED/COULDN'T STOP DRINKING:

EVER NEED A MORNING DRINK:

EVER ATTENDED AA:

DRINKS OF ALCOHOL TODAY:

NONPRESCRIBED DRUG USE TODAY:

AGREES TO RAND STUDY:

BACKGROUND total:

SOC. DESIRABLE RESPONSE total:

LIFE EVENTS total:

JELLINEK 1:

JELLINEK 2:

JELLINEK 3:

JELLINEK total:

CAGE total:

AUDIT total:

MAST total:

Microcomputer Client Information Sheet

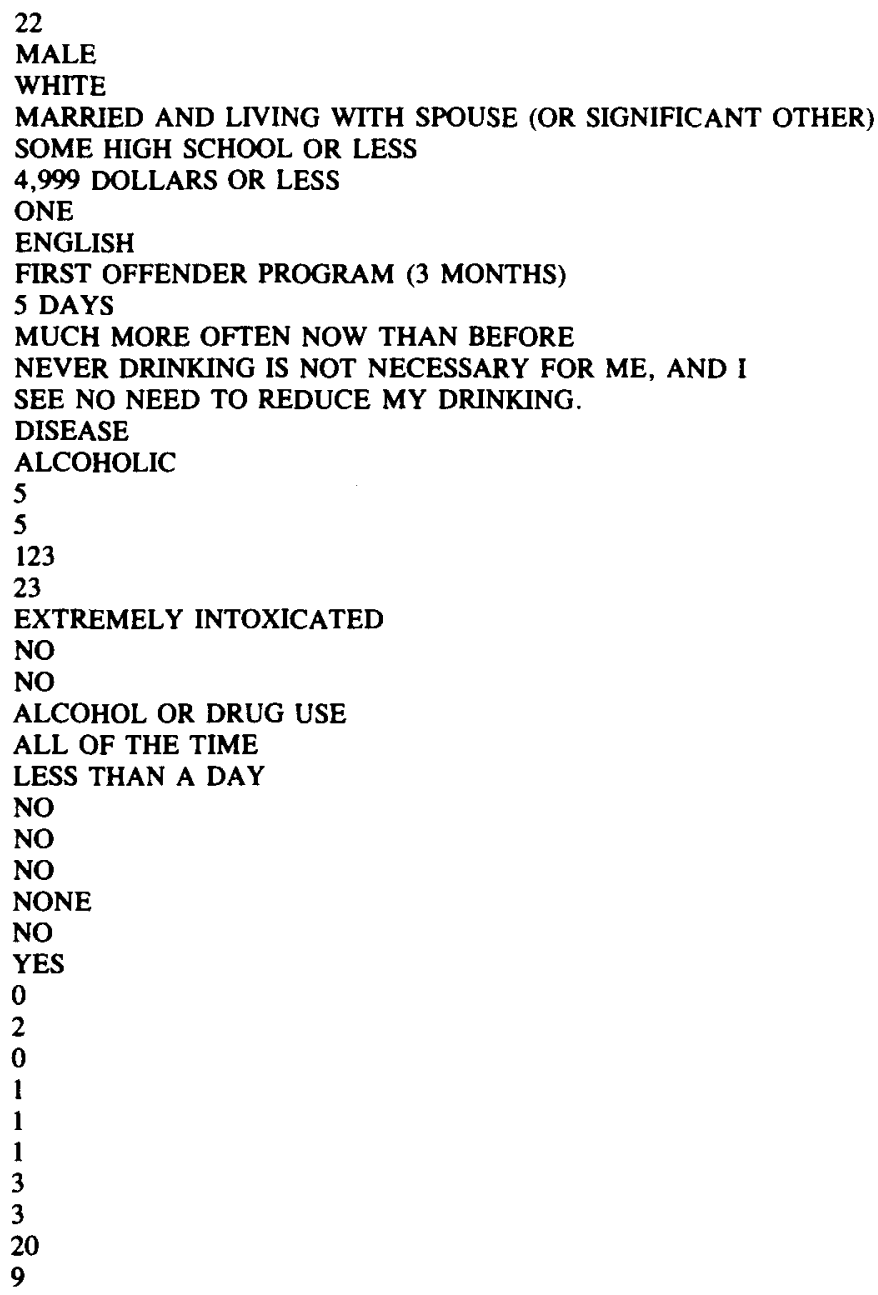

$31 \%$ of the respondents indicated that the computer interview was "a lot easier," $12 \%$ indicated "a little easier," $50 \%$ reported "about the same," $7 \%$ reported "a little harder," and 1\% indicated "a lot harder."

\section{Summary of Pilot Study}

The preliminary results of the pilot study suggest that MAS is a feasible methodology for collecting intake data at DUI treatment programs. Moreover, respondents tend to provide internally consistent data and to have very few problems with the microcomputer interview. Future analyses will examine methodological effects of varying the nature and placement of frequency-of-alcohol-use response choices within the interview.

\section{REFERENCES}

ALLEN, B., SKINNER, H. A. (1987). Lifestyle assessment using microcomputers. In J. N. Butcher (Ed.), Computerized psychological as sessment (pp. 108-123). New York: Basic Books.

BABOR, T. F., Grant, M. (1989). From clinical research to secondary prevention: International collaboration in the development of the Alcohol Use Disorders Identification Test (AUDIT). Alcohol Health \& Research World, 13, 371-374.

Babor, T. F., Stephens, R. S., MARLATt, G. A. (1987). Verbal report methods in clinical research on alcoholism: Response bias and its minimization. Journal of Studies on Alcohol, 48, 410-424.

Cronbach, L. J. (1951). Coefficient alpha and the internal structure of tests. Psychometrika, 16, 297-334.

Fleming, M. F., \& BARRY, K. L. (1991). A three-sample test of a masked alcohol screening questionnaire. Alcohol \& Alcoholism, 26, 81-91. 
GFROERER, J. (1985). Influence of privacy on self-reported drug use by youths. In B. A. Rouse, N. J. Kozel, \& I. G. Richards (Eds.), Self-report methods of estimating drug use: Meeting current challenges to validity (DHHS Publication No. ADM 85-1402, pp. 22-30). Washington, DC: U.S. Government Printing Office.

Hays, R. D., Hayashi, T., Stewart, A. L. (1989). A five-item measure of socially desirable response set. Educational \& Psychological Measurement, 49, 629-636.

Hesselbrock, M., Babor, T. F., Hesselbrock, V., Meyer, R. E., 2 Workman, K. (1983). "Never believe an alcoholic"? On the validity of self-report measures of alcohol dependence and related constructs. Internarional Journal of the Addictions, 18, 593609.

Hilton, M. E. (1986). Inconsistent responses to questions about alcohol consumption in specified settings. American Joumal of Drug \& Alcohol Abuse, 12, 403-413.

Mayfield, D., Mcleod, G., Hall, P. (1974). The CAGE questionnaire: Validation of a new alcoholism screening instrument. American Joumal of Psychiatry, 131, 1121-1123.

Meier, S. T., Lambert, M. E. (1991). Psychometric properties and correlates of three computer aversion scales. Behavior Research Methods, Instruments, \& Computers, 23, 9-15.

Poikolainen, K., KarkKainen, P. (1985). Nature of questionnaire options affects estimates of alcohol intake. Journal of Studies on Alcohol, 46, 219-222.

Selzer, M. L., Vinokur, A., Van Rooijan, L. (1975). A selfadministered Short Michigan Alcoholism Screening Test (SMAST). Journal of Studies on Alcohol, 36, 117-126.

Skinner, H. A., Allen, B. A. (1983). Does the computer make a difference? Computerized versus face-to-face versus self-report assessments of alcohol, drug, and tobacco use. Joumal of Consulting \& Clinical Psychology, 51, 267-275.

Sobell, L. C., Maisto, S. A., Sobell, M. B., Cooper, A. M. (1979). Reliability of alcohol abusers' self-reports of drinking behavior. Behavioral Research \& Therapy, 17, 157-160.

Williams, G. D., Aitken, S. S., Malin, H. (1985). Reliability of self-reported alcohol consumption in a general population survey. Journal of Studies on Alcohol, 46, 223-227.

ZUNG, B. J. (1979). Psychometric properties of the MAST and two briefer versions. Joumal of Studies on Alcohol, 40, 845-859. 